\title{
Plano Preliminar das Facilidades Materiais para a Recreação em Brasilia (*)
}

Ethel Bauzer Medeiros

"The world of tomorrow, with its increased leisure and its promise that a much higher proportion of the family budget can be allocated to various forms of recreation, presses upon us, demanding that we plan cities in which far more space is provided for leisure activities than is reserved for recreation in the cities of today". Wayne R. Williams - arquiteto. $(30)\left({ }^{\star \star}\right)$

\section{EXPOSIÇÃO DE MOTIVOS}

Para fundamentar e justificar as recomendações feitas aqui quanto às facilidades materiais para a recreação na nova capital, vamos precedê-las de uma formulação clara dos princípios e regras que serviram de base ao nosso planejainento, dos valores que o nortearam, dos objetivos buscados, enfim, da silossofia de recreação adotada. Vejamos, inicialmente, o que se entende por recreação.

\section{CONCEITO DE RECREAÇÃO}

Consideram-se atividades recreativas tôdas aquelas com que as pessoas (de qualquer idade) ocupam, por livre escolha e de forma salutar, as suas horas de lazer, sem ter em mira outro fim que não o prazer das próprias atividades, nas quais costumam encontrar não apenas satisfação intima, mas oportunidade para recriar. O que importa não é, pois, o tipo de ocupação, porém a disposição de espírito, a atitude mental de quem a elas se entrega, achando-se por isto entre as formas mais comuns de recreação coisas tão variadas quanto desportos e leitura, filatelia e dança, excursões e canto.

(*) Trabalho feito em setembro de 1959, por solicitaçấo do Professor ALFrEDó Colombo, Diretor da Divisão de Educação Física do M.E.C., para at znder a pedido da I UV VACÁ sôbre dados necessários à elaboração de um plano de recreação para Brasilia.

$\left.{ }^{(* *}\right)$ Os números que figuram entre parênteses correspondem aos itens da bibliografia anexa. 


\section{CONTRIBUIÇÕES DA RECREAÇÂंO À VIDA HUMANA}

A recreação é necessidade humana básica, é lemento vital para todos nós. E' indispensável não só à criança, como também aưs que estão na adolescência, na idade adulta e na velhice : é fundamental à vidia na família, no grupo de vizinhança e na comunidade ; é tão importante para cas pessoas sadias quanto (se não mais ainda) para as doentes; é necessária ti anto aos que vivem em familias organizadas quanto àqueles que se acham $_{1}$ em asilos, orfanatos, patronatos e reformatórios, aos plenamente capazes e à os portadores de deficiências físicas ou mentais, aos que freqüentam a escipla e aos que nunca puderam beneficiar-se da educação formal.

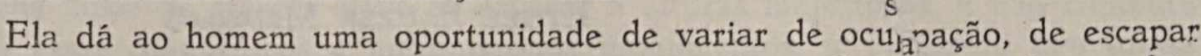
a rotina que o trabalho comumente representa; oferece-lhe $\mathrm{I}_{1}$ neios de aperfeiçoar sua saúde física e mental bem como seu ajustamento ça grupo social ; contribui para preservar-lhe o equilibrio emocional. Trai --lhe: alegrias, relaxamento das tensões neuromusculares, possibilidades i te desenvolver sua auto-estima, meios de exprimir sua individualidade em ur. $\mathrm{n}^{2}$ ambiente de prazer, satisfação na vida, solidariedade dentro da familia, ¿ eficiência no próprio trabalho e, até, espirito de comunidade. Por interméd io das atividades recreativas, êle pode compensar o tédio resultante de tấ refas monótonas, dar vazão às energias reprimidas durante muitas de sußos atividades habituais (sedentárias ou despidas de elementos de criação) e ta restabelecer o equilíbrio nervoso, após longas horas de trabalho sob tensão. s Sua melhor contribuição é, porém, permitir ao homem encontrar-se a si n. lesmo e se realizar, auto-afirmar-se através de uma verdadeira recriação.

Poderíamos indicar como os principais objetivos da recreaçãc ?: enriquecer a vida, por meio da utilização construtiva das horas de lazer, e propiciar a expressão dos interêsses humanos, por intermédio das artes p lásticas, cla música, da dança, da atividade dramática, dos jogos e despor tos, da apreciação da natureza, das atividades sociais e daquelas referentes á ? todo o mundo do espírito.

\section{A RECREAÇÃO NA SOCIEDADE CONTEMPORÂNEA}

Sempre presente à sociedade, como necessidade fundamental do home. $\mathrm{m}$, a recreaşão viu sua importância crescer enormemente de vulto na époc a atual. O desenvolvimento cientifico dos últimos séculos trouxe-nos alterações tão radicais e amplas, que chegou a produzir uma verdadeira revolução no "modus. vivendi" do homem. Embora de um passado muito recente, a ciência e a máquina resultaram numa aceleração da mudança social, sem precedente na história da civilização. As modificações das condições exteriores da vida humana (e, portanto, dos seus interêsses) repercutiram profundamente nas tradições culturais e nas instituições sociais. Êste aspecto das conseqüências sociais do desenvolvimento científico salta aos olhos de todos nós. Outro lado, porém, não tão óbvio, merece exame. Enquanto o mundo em que vivemos está sendo ràpidamente transformado pela ciência (com a eletrônica, os antibióticos, os aviões a jacto etc.), nossos hábitos de pensamento e ação persistem inalterados, em apêgo obstinado às tradições e às 
instituições de uma era pré-cientifica. "É impossivel", - diz JohN DEwey, - "chegar a exagêro ao descrever a confusão mental e a desordem prática que resultam quando os efeitos exteriores e físicos são planejados e reg̣ulados, enquanto que as atitudes mentais, de cuja direção êles dependem, são deixadas ao acaso, à tradição e ao dogma... Apesar, pois, de todo o passado, a grande revolução científica ainda está por ocorrer. Ela terá lugar quando os homens, em conjunto e em colaboração, organizarem o seu conhecimento e aplicarem-no na consecução e na preservação dos valores sociais e quando, sistemàticamente, utilizarem processos científicos no contrôle das relações humanas e na direção dos efeitos sociais do nosso vasto maquinismo tecnológico. Grandes, que foram, as mudanças sociais do século passado não se poderão comparar às que irão surgir, quando a nossa fé no método cientifico puder patentear-se em trabalhos sociais".

A industrialização trouxe-nos não sòmente uma diminuição do número de horas de trabalho e uma elevação do nosso padrão material de vida (pela aplicação intensiva da máquina ao cotidiano), como também um moviment’ inigualável de urbanização e uma subdivisão muito maior do trabalho. Se, por um lado, ela resultou em menor dispêndio de energia humana, menos cansaço físico no trabalho, a par de mais hozas de lazer, acarretou, por outro, os conflitos e as dificuldades de vida inerentes às aglomerações urbanas, bem como uma €norme especialização de ocupações, acompanhada da monotonia e do fastio das tarefas repetidas em rotina. O tecelão antigo podia orgulhar-se do que criava, porque partia do simples fio e chegava a um produto final, que tiazia o seu nome ou a sua marca de fabricação. O operário de hoje realiza apenas uma operação incolor nos modernos teares de uma fábrica bem equipada. Desconhece, via de regra, onde o tecido pronto vai acabar, não encontrando, provàvelmente, satisfação especial em seu limitado encargo. Como não acha oportunidades para exprimir sua individualidade no terreno, profissional, não pode sentir o prazer que acompanha a execução integral de uma obra. Então, é fora do trabalho que procura (e deve) obter tais satisfaçôes, indispensáveis à sua estabilidade emocional e ao seu bem- estar físico. A mecanização dos processos de produção converteu o contentamento, antes encontrado no trabalho, em privilégio raro. Poucos de nós ainda logram experimentar o prazer de acompanhar a transformação completa da matéria-prima em um produto acabado ter lugar nas próprias mãos. A utilização crescente das máquinas promete privar ainda maior número de pessoas da alegria do trabalho criador, substituindo-o por mera atividade para ganhar o pão.

O mesmo problema aparece, ainda que sob prisma diferente, em outros campos da atividade profissional. As pessoas que trabalham sob tensão continua ou em ritmo necessàriamente acelerado (como os aviadores, os cirurgiôes cu os motoristas profissionais, por exemplo) ou aquelas que se entregam a ocupações dominadas pela competição (como as industriais e comerciais) têm necessidade, para manter a saúde física e o equilíbrio psíquico, de mudar de atividade nas horas vagas, a fim de conseguir certo relaxamento muscular e nervoso, algum desafôgo de inquietações, receios e angústia. 


\section{A QUESTÃO DO BOM APROVEITAMENTO DAS HORAS DE LAZER}

O aproveitamento das horas de lazer, cujo número tende ainda a crescer, passou, então, a constituir mais uma preocupação dos governantes e, em especial, dos responsáveis pela educação pública. O conceito de recreação sofreu uma modificação radical, quando ela deixou de ser vista exclusivamente como elemento útil ao descanso (quando não coisa meramente tolerada, diversão inocente ou maneira de matar o tempo), para atingir o "statur." atual de parte integrante do processo educativo normal. $\mathrm{Na}$ medida em que o homem foi tomando consciência da sua necessidade básica de se recrear e na proporção em que foi dispondo de mais horas de lazer, foi-se evidenciando a importância de uma educação para a recreação. A sociedade convenceu-se, então, de que não bastava oferecer terreno e material para que as atividades buscadas nas horas de lazer fôssem construtivas e de fato, recriadoras. Percebeu que era preciso formar o homem para bem utilizar o seu tempo livre, apontar-lhe claramente os benefícios de uma recreação sadia, ampliar-lhe os horizontes (mostrando-lhe as diferentes oportunidades de se divertir), oferecer orientação e liderança para as suas atividades e, notadamente, nêle estimular a formação de hábitos de participação ativa. A recreação transformou-se, então, em responsabilidade dos podêres públicos, em função governamental, não por consentimento dos governados mas por sua solicitação expressa.

\section{LUGAR DA RECREAÇÃO NO PLANEJAMENTO DAS CIDADES}

"Many new towns have become large areas of suburbia, utterly devoid of endearing characteristics. The lessons of these towns must be taken to heart - new towns and redevelopment planners must be forced to appreciate both the "intimacy" of the small "open space" and the playing fields and learn to couple these apparently conflicting ideas in residential area design. (Parks and Sports Grounds, Londres : Set., 1958.)

Eis porque a recreação passou a constituir, em nossos dias, elemento essencial do desenvolvimento das cidades, sendo agora encarada como fator de beleza, de enriquecimento da vida, de felicidade e até de maior produtividade. Tornou-se imprescindivel incluir no plano-mestre das cidades uma previsão de longo alcance das áreas e facilidades materiais para a recreação, reservando-se locais onde tôdas as pessoas, independentemente de idade, nivel єconĉmico e ocupação, pudessem passar as suas horas de lazer, entregues a atividades prazerosas e salutares. Um plano desta natureza inclui, portanto: parques infantis que possam ser freqüentados com facilidade $e$ segurança, todos dotados de espaço suficiente para pré-escolares e escolares darem vazão às suas energias, sem conflito; locais onde os adolescentes encontrem possibilidades de praticar seus jogos e desportos prediletos e bem assin as atividades sociais e culturais que mais os interessam; lugares adequados para os adultos poderem reunir-se, conversar, ler, realizar festas, realizar jogos, fazer assembléias, exposições, concertos etc.; facilidades para 
a. familia divertir-se em grupo, realizar piqueniques, freqüentar uma piscina pública, recrear-se em bibliotecas, museus, jardins, praças e pontos de beleza panorâmica. Para tanto, é óbvio, há necessidade de terreno amplo, equipamento \& material convenientes, boa manutenção e, sobretudo, liderança adequada - coisas que demandam um orçamento ponderável. A opinião pública deve, então, ser esclarecida, no sentido de compreender que tais coisas não são supérfluas nem constituem luxo a "ficar para depois se houver reservas", mas representam algo tão necessário à vida da comunidade quanto as escolas, as rêdes de água e esgôto, o calçamento das ruas, o sistema de transportes públicos etc. etc. As próprias companhias particulares já mostram reconhecer tal coisa, ao inverterem avultado capital em programas de recreação para os seus empregados, tendo em vista os benefícios, assim obtidos, de melhores relações humanas, maior produção e, sobretudo, menor "turn over" do pessoal.

Só nc ano de 1953, trinta mil companhias industriais e comerciais norteamericanas gastaram em programas recreativos a importâncias de 800 milhões de dólares.

Outrc indício de que a recreação é tida como elemento fundamental à vida plena é o fato do seu aparecimento, como serviço regular, em hospitais, escolas de todos os niveis e tipos, planos de ação dos diferentes credos religiosos, requisitos básicos dos grandes conjuntos residenciais, orfanatos e asilos fara a velhice, bem como instituições dedicadas à recuperação dos portadores de deficiências físicas ou mentais.

\section{PRINCÍPIOS BÁSICOS AO PLANEJAMENTO DAS FACILIDADES MATERIAIS PARA A RECREAÇÃO DE UMA COMUNIDADE}

O planєjamento geral do sistema de recreação para uma comunidade
deve visar: - a maior utilização possível, por parte do público das áreas destinadas a recreação ;

- economia de construção e de manutenção:

- facilidade de acesso, de funcionamento e de supervisão, dentro das condiçôes fundamentais de segurança;

- máximo de arte e de aproveitamento das belezas naturais.

Lembremos, ainda, os principios fundamentais relativos às condições materiais, formulados durante a "National Facilities Conference" (16), que teve lugar em 1947, na cidade de Chicago:

a) A comunidade moderna necessita de condições materiais para os seus programas de atletismo, recreação, educação física e educação da saúde.

b) A distribuição, à localização e o tamanho destas comunidades estarão intimamente ligados ao aspecto global da comunidade - ao seu seu padrão geral. 
c) Tais facilidades devem ser planejadas em relação às outras características físicas, sociais e econômicas da comunidade.

d) A base do plano-mestre de cada comunidade há de ser um estudo das necessidades sentidas pela própria comunidade.

e) Tais facilidades devem ser planejadas tendo em vista os recursos potenciais existentes.

f) As modificações são inevitáveis e hão de ser levadas sempre em consideração no planejamento.

g) Educação e recreação terão programas de ação amplos, que se devem complementar e suplementar, cada qual exigindo as suas facilidades.

h) As áreas destinadas à prática de atletismo, da recreação, da educação física e da educação da saúde devem atender aos princípios de urbanismo.

i) O prédio escolar há de ser planejado tendo-se em vista a sua utilização como centro de educação e de recreação.

i) Os conhecimentos e a experiência do pessoal das escolas, parques e serviços de recreação devem ser amplamente utilizados no planejamento, no desenvolvimento, no funcionamento e na manutenção dessas facilidades.

1) As acomodações para os parques, escolas e outras áreas de recreação destinadas a servir aos grandes núcleos residenciais (públicos ou particulares) devem ser planejadas, em colaboração, pelos responsáveis por tais núcleos e pelas autoridades escolares, de recreação e dos grandes parques.

in) Tal planejamento em conjunto para o desenvolvimento das facilidades e a sua utilização exige um acôrdo prévio (sôbre normas, regras e responsabilidades) entre os vários serviços interessados.

Antes de passar ao planejamento pròpriamente dito, convém acrescentar a tais considerações alguns dos "Principios Fundamentais da Recreação na Coraunidade", arrolados pela "National Recreation Association" dos E.U.A., a saber:

a) Os programas para o uso do lazer na comunidade devem estender-se ao ano inteiro.

b) E' responsabilidade de tôda a comunidade propiciar oportunidades de recreação a todos os cidadãos, sendo necessário, portanto, conseguir-se, o mais prontamente possível, apoio financeiro ao programa de recreação, por meic de taxação pública, feita por algum serviço do govêrno local.

c) Cada nova escola construida deve ter um mínimo de espaço à sua volta, para o recreio das crianças.

d) Quase todos os novos prédios escolares terão que contar com um auditório, de preferência no pavimento térreo, construído de maneira a támbém poder ser utilizado pela comunidade.

c) Se não existir, nas escolas ou em outros lugares, um local adequado para a reunião dos grupos da comunidade, a própria comunidade deve providenciar um prédio para tal fim.

f) Tôda criança de menos de dez anos, que viva numa cidade, há de ter a possibilidade de brincar num parque de recreação infantil, sem precisar afastar-se mais de $400 \mathrm{~m}$ da sua casa. 
g) Tôda comunidade deve oferecer espaço suficiente para os rapazes dedicarem-se a desportos como o futebol, por exemplo. natação.

h) Em tôda comunidade rão de existir facilidades apra a prática da

i) Tôda criança deve encontrar oportunidade, quer em sua casa quer em terreno oferecido pela municipalidade, de ter um jardinzinho, onde possa observar o crescimento de plantas suas.

j) Em cada nova zona urbanizada, deve-se separar, para fins de recreação, uma percentagem razoável da área total (da mesma forma por que se destina parte do terreno para a construção das ruas).

\section{FASES DO PLANEJAMENTO-GERAL}

Das fases seguintes, do trabalho de planejamento de um sistema de recr

- adoção de padrões e normas ;

- levantamento das condições existentes (análise da comunidade, dos fatôres sócio-econômicos que afetam as suas atividades recreativas e estudo das condições topográficas);

- avaliação da situação e fixação de um plano;

- desenvolvimento de um plano de ação (que compreenda a previsão de programas, o estudo do financiamento de tais programas e da sua direșão, bem como da propaganda e das relações públicas necessárias ao seu bom êxito),

cridaremos tão-sómente da primeira, isto é, dos aspectos mais amplos do planejamento fisico das áreas para a recreação, dos padrões e normas iєcomendáveis para tais áteas.

() Uanto à segunda, queremos apenas ressaltar a importância de um estudo cuidadoso das comunidades envolvidas, para a obtenção de estimativa sôbre o crescimento populacional, de dados sôbre a distribuição de idades nos vários conjuntos de vizinhança, (bem como sôbre o nível sócio-econômico nas diferentes zonas e sôbre os hábitos de recreação de tais pessoas). $E^{\prime}$ claro que as necessidades de recreação de uma cidade estão intimamente ligadas: ao indice de crescimento da sua população: à densidade da população nas diferentes zonas (ou seja, à razão entre determinado número de pessoas e a proporção da área total em que vivem): à composição da população de acôrdo com os vários grupos de idade; e às condições locais de topografia e clima. Será indispensável, também, proceder-se a um "survey" das necessidades de recreação sentidas pela comunidade e bem assim da tendência ce:al das atividades procuradas pelos diferentes grupos, nas suas horas de lazer. O nível de educação, as condições de saúde e as várias outras características sociais e econômicas da população terão ainda de ser levadas em conta, no estudo dos conjuntos de vizinhança.

No que diz respeito às fases restantes, não nos parece demais salientar o fato de que sòmente uma nrientação segura, feita por pessoal capaz e espe- 
cializado em recreação, poderá permitir o bom aproveitamento das facilidades nıateriais a ela destinadas. Para que o sistema de recreação pública possa trazer benefícios reais à comunidade, é imprescindivel o trabalho sistemático e coordenado de recreadores com a devida formação profissional, em lugar do pessoal improvisado em alguns meses q,ue costuma atuar como simples "fiscal de brincadeiras".

\section{8. ÁREAS PARA A RECREAÇÃo PÚBLICA}

Porque existe um reconhecimento tácito de que a recreação é uma necessidade humana básica, a lei, a prática e a opinião pública defendem a idéia de que é uma função essencial dos podêres públicos providenciar praças, jardins, parques, museus e' outros locais para o recreio dos cidadãos. Mas só raramente tem -se o ensejo de escolher cedo os melhores lugares para tais centros de recreação, sendo o comum lotear-se a terra, construirem-se as casas e permitir-se a sua ocupação, antes que surja a consciência real da necessidade de espaço público para as atividades recreativas. A essa altura, porém, o terreno já está retalhado, parcialmente vendido e edificado, subiu muito de custo, achando-se então bem reduzidas as possibilidades de um bom aproveitamento das áreas mais propícias (por sua proximidade ein relação às escolas e aos grupos de vizinhança, por sua beleza e por seus acidentes naturais).

Como foi salientado pela comissão de urbanismo do "National Resources Committee", o problema mais evidente na recreação urbana decorre, em alğumas cidades, da ausência de espaço suficiente para a recreação; em inúmeras outras cidades, êle é ainda agravado pela má distribuição (e conseqüente ineficiência) das áreas recreacionais existentes. Não haverá real proveito em se plantarem aqui e ali pequenos conjuntos de balanços, gangorras e escorregas, de côres vivas, mas feitos, geralmente, de material pouco resistente ao uso intensivo que vão sofrer nem, por outro lado, vantagem em concentrar todos os recursos na criação de um único "play-ground", embora modelar. O importante é o planejamento geral, é uma previsão que abranja tôdas as zonas a que se pretende servir, tendo em vista uma distribuição ractonal cias facilidades (as quais serão inteiramente diferentes numa zona de apartamentos espaçosos e noutra fabril, por exemplo) as dimensões e a forma das áreas disponiveis, a topografia das mesmas, bem como as redondezas em que elas se encontram (a densidade de população da zona em que estão, as escolas próximas, as facilidades de comércio, as vias de acesso e a intensidad こ do trânsito). E, nesse planejamento, nada pode substituir a previsão de espaço, de áreas de tamanho adequado, bem situadas em relação aos grupos de vizinhança e às vias de acesso. A eficiência de qualquer dessas áreas vai depender da sua relação com as demais facilidade's de recre:o, pois, evidentemente, a utilização de cada local afetará a dos demais. O planejamento de cada área em separado resulta, quase que sempre, na escolha de locais muitc afastados entre si, demasiadamente próximos ou, ainda, não relacionados às facilidades escolares da comunidade. Para se lograr a melhor utilização de cada área, tôdas elas serão planejadas como parte de um sistema 
unificado, que atenderá à cidade inteira. Êste planejamento global irá evitar a superposição de serviços, assegurar a aplicação de padrõe's iguais de acessibilidade (de acôrdo com a densidade da população) e patentear as oportunidades de relacionar as facilidades de récreação não só entre si mas com os outros serviços locais. Desta maneira, poder-se-á conseguir uma distribuição eqüitativa dos recursos, u'a maior cooperação entre os vários grupos de vizinhança e uma coordenação dos esforços de tôdas as pessoas implicadas na direção dos programas.

Os centros de tecreação de cada conjunto de vizinhança devem ter uma localizaçâa central, sendo necessàriamente afastados das ruas de tráfego mais intenso, das estradas de ferro ou de outras fontes potenciais de perigo. Os grandes parques estarão em zona servida por transportes públicos, para garantir-lhes uma alta freqüência. Suas áreas de serviço hão de ser limitadas, o mais possivel, por obstáculos naturais (lagos, canais, rios ou morros) ou por barreiras artificiais, como estradas de rodagem ou de ferro.

Os primeiros fundos hão de ser empregados na aquisição do terreno e no preparo, antes que a valorização o torne de custo proibitivo, deixando-se para segundo lugar a compra do equipamento e as edificações. Queremos citar, a propósito, nossa experiência pessoal num dos maiores e mais bem aparellhados parques infantis do Rio, o qual, não obstante, mostrava-se alagado e impraticável durante dias, após uma chuva forte, tendo ainda a desvantagem de afastar as crianças de tôda uma de suas áreas, por estar ela constantemente exposta a vento forte. Havendo espaço suficiente e boa liderança, a própria comunidade encarregar-se-á (com benefícios reais para ela) das tenfeitorias necessárias, reconhecidas como de utilidade por todos. Vale a pena recordar aqui os exemplos dos "adventure playgrounds", que vêtn florescendo na Suécia, Dinamarca, Suiça, Inglaterra e E.U.A., como se verá adiante, em mais detalhe.

\section{O PROBLEMA DOS PADRÕES DE ESPAÇO}

Indicaremos aqui os padrões de espaço comumente recomendados para os diferentes tipos de áreas de recreação, com a devida ressalva de que precisam ser tomados como simples pontos de referência, quando se estudar a maneira de melhor atender às condições locais, em cada caso. Salientamos, air da, que as áreas de recreação, além de eficientes precisam ser atraentes, forque o público exige não apenas uma solução adequada dos problemas de espaço, de circulação e de construçāo, mas, ainda beleza.

A fixação de padrões especiais implica um grau considerável de acôrdo entre os cspecialistas, quanto às necessidades e aos interêsses de recreação das pessıas, bem como ao espaço e às outras condições materiais necessárias para atendê-las. E' preciso, pois, relacionar sempre tais exigências teóricas de espaço ao tipo de população da cidade. Feitas estas advertências iniciais, apontemos o padrão geral mais comumente aceito : tantes.

$4000 \mathrm{~m} 2$ (ou, mais precisamente, $4047 \mathrm{~m} 2$ ) para cada centena de habi- 
Ele IEpresenta apenas um indice da adequação do espaço oferecido, havendo necessidade, ainda, de cuidar que tais áreas sejam bem distribuidas pela cidade e ofereçam possibilidade para tipos diferentes de recreação. Alén: disto, certas áreas com feições características (como aquelas de topografia muito variada, campo aberto, região florestal ou zona de rio) não se podem submeter a fórmulas específicas de espaço. Acrescente-se a tais circunstâncias a recessidade de se levar em conta a tendência de crescimento da poulação e as seguintes considerações, que irão influir nas exigências futuras de espaço dos parques e das áreas de recreação :

a) As próprias condições, em mudança rápida, das cidades (menos horas de trabalho para os seus habitantes e, portanto, mais lazer, ascensão do padrão de vida, proliferação da recreação comercializada, desaparecimento progressivo dos espaços abertos, tráfego intenso etc.) evidenciam a urgência da aquisição de mais terras para os parques e para a recreação municipal, em. beneficio da população urbana. (Dai a necessidade de padrões especiais mais éievados para tais áreas e de maior nummero de oportunidades de recreação de fácil acesso.)

b) A competição crescente em tôrno do espaço disponivel, o custo ascensional cio terreno e da construção forçada uma cooperação maior entre as várias organizações na aquisição, no aproveitamento, no funcionamento e na utilização das áreas de recreação. (Com esta cooperação será possivel atingir-se padrões mais altos e facilidades mais diversificadas.)

c) As areas que orlam as grandes cidades devem merecer maior consideração, pois nelas está se processando grande crescimento de população. (Donde a necessidade da criação de amplos cinturões verdes, à volta dos grandes centros urbanos.)

di A multiplicação e o aperfeiçoamento das estradas de rodagem, os fim-de-semana" mais longos e o crescente interêsse público pelas tividades ao ar livr z tenciem a resultar na solicitação de parques maiores.

Por f̂stes motivos, é imprescindivel uma reavaliação periódica (feita de cinco em cinco anos, pelo menos) das facilidades e necessidades de recreação, bem como das respectivas tendências e planos de longo alcance. A tarefa do planejador há de ser vista, então, como trabalho que nunca se pode dar por encerrado, como processo continuo de criação.

\section{8b. TIPOS DE ÁREAS MAIS IMPORTANTES PARA A RECREAÇÃo}

Consideram-se habitualmente como de maior importância os seguirites tipos de áreas :

\section{Para a recreação ao ar livre}

1 - O "lote de recreio" ("playlot") - E' uma área reduzida, destinada às brincadeiras dos pequeninos. Serve de complemento ao lar, oferecendo a tais crianças experiências que, em geral, não lhes são possíveis em casa. Assume importância especial nas zonas residenciais muito populosas, devendo ficar a pequena distância, a pé, da maioria das casas a que atende e ser de 
fácil acesso para mães e filhos. Quando não fizer parte de um centro maior de recreaça a (um parque, por exemplo), será supervisionado pelos próprios pais ou por outros voluntários. O "Guide for Planning Facilities" (16) recomenda uma área de $930 \mathrm{~m} 2$ para cada lote, enquanto que Butler (3) sugere um minimo de $460 \mathrm{~m} 2$ e uma média de $930 \mathrm{~m} 2$.

Seu equipamento costuma incluir caixas de areia, trepa-trepa, mesas e bancos, єsradas, escorrega, bebedouros e tanque de água. Contará corn um espaço livre, suficiente para que as crianças andem bem nos seus veículos (velocipedes, rema-remas etc.), dotado de um abrigo para os dias de mau tempo ou de calor excessivo, além de árvores para efeito de sombra e embelezamento a cêrca viva ou grade, para proteção. O número total de lotes de recreio será proporcional ao tamanho da comunidade e ao grupo de pré-esculares nela encontrado.

II -- O "parque de recreação" ("playground") - E' uma área bem maior, especialmente planejada para as crianças de cinco a quatorze anos bem como para grupos de família, embora, via de regra, inclua um recanto para o usc exclusivo dos pequeninos, particularmente no caso de não haver na proximidade "lotes de recreio". Este setor há de ser bem separado dos demais, por meio de vegetação adequada ou de uma cêrca.

Recomenda-se localizar parques assim à distância de 400 a $800 \mathrm{~m}$ de cada tamilia, segundo as condições de cada conjunto de vizinhança. Sempre que possivel, êles situar-se-ão perto das escolas primárias ou serão a elas anexos. Sua área deverá variar de $12.140 \mathrm{~m} 2$ (para um grupo de vizinhança que conte com 2.000 pessoas) a $24.280 \mathrm{~m} 2$ (para 5.000 almas). As necessidades totais do espaço devotado a "playgrounds" em uma cidade são estir.adas em $4.000 \mathrm{~m} 2$ para cada 800 pessoas da sua população atual. Êstes padrões são amplamente adotados, embora nos últimos três anos venha surgindo um tendência a reunir em áreas bem mais amplas a escola, o parque de recreação e a praça. Assim, por exemplo, o seminário sôbre facilidades para a recreação, patrocinado pelo "Athletic Institute" de Chicago, em 1956, propôs uma combinação do centro de recreação com o parque de recreação, numa área igual ou superior a $60.700 \mathrm{~m} 2$. Para a escola-parque (na qual está incluida uma escola-classe elementar) foi proposta uma área semelhante, recomendando-se para ambas um raio de ação de $400 \mathrm{~m}$ a $800 \mathrm{~m}$ de cada casa.

0 "California Committee on Planning for Recreation, Park Areas and Facilities" recomendou, em 1956, um centro de recreação para cada conjunto de vizinhança, sob a forma de um "recreation park", ou seja um parque combinado com uma escola elementar. Propuseram-se, então, padrões de espaço para os vários conjuntos de vizinhança, tendo-se em vista seu tipo, seu tamanho e sua densidade populacional. Recomendaram-se áreas de $64.750 \mathrm{~m} 2$ a $80.940 \mathrm{~m} 2$ para grupos de vizinhança de 2.000 a 4.500 pessoas, varianclo o raio de ação de um parque assim de 200 a $600 \mathrm{~m}$ de cada casa.

Citamos estas propostas, mais recentes, com o intuito de evidenciar as modificações que estão ocorrendo no conceito primitivo de "parque de 
recreação" e de "parque de vizinhança". Nelas se reconhece : a praticabilidade cie se combinar as funções do parque, do "playground" e da escola em um único ambiente; a necessidade de um planejamento, em cooperação, por parte das autoridades escolares e municipais na aquisição e no aproveitamento das áreas que irão servir à recreação de ambas; a importância da obtenção de propriedades maiores que as exigidas pelos padrões anteriores; o interêsse em reduzir o raio de serviço das áreas de vizinhança. Esclareça-se que tais propostas levaram em conta os padrões especiais aconselhados pelo "National Council on School House Construction" para a escola elementar, a saber, "uma área minima de $20.200 \mathrm{~m} 2$ para a escola, acrescida de $4.000 \mathrm{~m} 2$ pára cada cem alunos de matrícula efetiva".

Segundo os padrões tradicionais, ainda prevalentes, o parque de recreação anexo à escola deve incluir : um recanto para os pequeninos, com aparelhos de proporção e pêso adequados ao grupo, bem como áreas livres para as brincadeitas e bancos para os acompanhantes das crianças; uma área mais ampla, com aparelhos, para as crianças maiores, contendo escorrega, balanços, barras e escadas horizontais, além de trepa-trepa; uma área pavimentada para os jogos organizados e outras atividades lúdicas : um espaço aberto para as brincadeiras livres (uma área nivelada para os jogos infantis de pequena organização e para as atividades livres); um campo para os grandes jogos (uma ćrea ampla, nivelada, para jogos como o futebol $e$ as atividades dos grandes grupos, podendo ainda servir para desfiles, cerimônias festivas etc.); um canto para as atividades mais sossegadas (ouvir histórias, fazer dramatizações, realızar trabalhos manuais e jogos de salão), que deve ficar bem separado das zonas de brincadeiras ativas: um tanque para brincadeiras com água, que pode ser tanto de vadiar como simples "spray pool" (de manutenção mais fácil e lugar de grande atração no verão); o recanto das nessoas iausas, com mesas e bancos para dar maior comodidade; um pavilhão contendo: banheiros, lugar para a guarda do material e, se possivel, um salão de recreio; jardim e áreas arborizadas para embelezar a paisagem.

III - O "campo de recreação" ("Playfield") - E' o centro princial das atividades ao ar livre de adolescentes e adultos, embora inclua, em geral, um "parque de recreação" para crianças, (como o delineado no item anterior), e sirva a muitos outros grupos. Via de regra, situa-se em local servido por transportes públicos.

Segundo a "National Recreation Association", deve ocupar uma área de $40.470 \mathrm{~m} 2$ a $80.940 \mathrm{~m} 2$, ao passo que o "Guide for Planning Facilities" (16) aconselha os seguintes padrões de espaço, denominando tal conjunto de "Community Park-School", por ser anexo a uma escola de nivel médio : anexo ao $1^{\circ}$ ciclo - ginásio, $101.170 \mathrm{~m} 2$; ou anexo ao $2^{\circ}$ ciclo colégio, $161.880 \mathrm{~m} 2$.

Habitualmente o campo de recreação compreende: um recanto para os pequeninos; um "playground"; uma pista de atletismo; campos separados de destortos para moças e rapazes; quadras de tênis e volibol; áreas gramadas para atividades variadas; piscina; prédio para recreação em 
ambiente fechado. Nesse prédio encontram-se salas para artes e trabalhos manuais, biblioteca, ginásio e auditório, bem como saletas para reuniões, sedes de clubes etc.

Em nuuitos dêstes campos de recreação existem, ainda: áreas para piqueniques (com mesas, bancos e lugar para cozinhar); concha acústica e teatro ao ar livre; zonas arborizadas para maior beleza paisagistica. E' comım disporem, também, de local para a realização de campeonatos interescolares.

IV - As praças, os parques e os jardins ("park") - No rol das facilidades materiais para a recreação, incluem-se comumente dois tipos de parques: o "parque de vizinhança", com suas árvores, moitas e alamedas; e o "grande parque", com $400.000 \mathrm{~m} 2$ ou mals de área; em sua maior parte conservada no estado natural, servindo habitualmente a tôda uma comunidade ou a parte de uma grande cidade. O primeiro costuma ser de um tipo mais formalista e, embora contenha por vêzes repuxos e tanques, pouco costuma oferecer à chamada recreação ativa. O segundo possui, em geral, áreas para jogos, locais para piqueniques e bem assim facilidades para acampamento. Ainda conta, às vêzes, com um jardim zoológico ou um viueiro de pássaros, um arboreto ou, então, um jardim botânico. Segundo a "National Facilities Conference" (16), é aconselhável um parque do segundo tipo para cada 50.000 pessoas.

$V$ - Zonas de preservação da natureza - São áreas que oferecem um contraste flagrante com o ambiente urbano circunjacente, abrangendo, via de regra, uma zona de $2.023 .500 \mathrm{~m} 2$ ou mais. Compreendem, além de estradas de rodagem, caminhos e atalhos para excursões a pé ou a cavalo. Quando possuem piscina, estádios, locais para acampamentos e outras facilidades cspeciais para a recreação, tais comodidades são, com freqüência, colocadas $\epsilon \mathrm{m}$ áreas bem separadas, a fim de não perturbarem o ambiente natural.

$V I$ - Praias e piscinas - Sempre que possivel, recomenda-se a construção de balneários perto das praias (desde que não interfiram com elas nem lhes prejudiquem a beleza natural). Aconselha-se, ainda, a preparação das áreas que lhes são adjacentes para servirem a piqueniques ou a outras formas de atividade recreativa.

Não kavendo no local tais condições naturais, pede-se a construção de piscinas, dotadas de acomodações para mudança de roupa e banhos de chuveiro. Cite-se, a propósito, a experiência norte-americana, que evidenciou a importância de se multiplicar o número de piscinas públicas, de construşão barata, destinadas a "banhistas apenas", ou seja, à maioria dos seus freqüentadores. Segundo foi apurado, o número de pessoas que procuram a piscina tão-sòmente para "tomar banho" é muito superior ao dos que visam nadar, sendo ainda mais reduzido o dos que pretendem divertir-se nos tranpolins.

VII - Locais para acampamentos - Trata-se de zonas que oferecem contraste com as condições de vida em que os habitantes da cidade normalmente se vêem. Distinguem-se aqui dois tipos de local: o destinado a 
acampamento diurno (cujos ocupantes voltam para casa ao fim do dia, não necessitando, pois, de previsões para pousada e, até, para cozinha, porque podem levar diàriamente um farnel); o previsto para periodos mais longos de tempo, para os "acampamentos de pernoite" (que devem contar com acomodações para dormir e preparar alimentos). Os primeiros hão de situar-se a uma distância conveniente da cidade, para que seja possível a sua fácil utilização. Os outros poderão ficar mais afastados da comunidade, sendo até ciesejável conseguir-se um certo isolamento. Ambos disporão de facilidades rara uma ampla variedade de atividades: rio ou lago (natural ou artificial) para pescar, remar e passear de barco, campos de jogos, zonas de muita vegetação para excursões e observação da natureza, bem como instalações sanitárias e fontes de água potável.

VIII - O teatro ao ar livre e o estádio, de preferência construídos em separado, embora em muitas comunidades êles tenham sido combinados num único local, por medida de economia.

O єstádio é necessário às grandes atividades desportivas, devendo conter campos de jogos, pista de atletismo, instalações sanitárias, sala de guardados, acomodações para os espectadores, lugar para o estacionamento dos carros, prevendo-se ainda iluminação adequada para as atividades noturnas.

Nos estádios mais novos têm sido construídos conjuntos separados de arquibancadas, a fim de tornar possivel a realização simultânea de atividades diferentes. Nas grandes cidades, a construção de um estádio municipal, localizado ém ponto central, com local amplo para a guarda de carros, está se tornando uma necessidade.

O teatro ao ar livre, que desde a antiguidade desempenha papel de importância na recreação pública, situar-se-á, sempre que possivel, em ambiente intimamente ligado à natureza, aproveitando-se um declive natural do terrenc para sentar os espectadores, como o "Red Rocks Theatre", em Denver.

Além do palco, contará com acomodações para os artistas e lugar adequado para a guarda de cenários e vestimentas. A primeira preocupação, porém, será, evidentemente, a de encontrar boas propriedades acústicas e iluisinação adequada para os espetáculos noturnos (concertos, representações teatrais $€$ cerimônias cívicas).

$I X$ - Nas outras áreas, planejadas para a recreação pública na Europa e na América do Norte, incluem-se, com freqüência, rinques de patinação e campos de golfe. Lembremos ainda a importância dos "parkways", estradas cle rodagem orladas de parques de recteio, jardins, museus, locais para piqueniques, mirantes etc.

\section{Para a recreação em ambiente fechado}

Yiesmo nas regiões em que as condições de clima são propícias a atividades freqüentes ao ar livre, deve haver acomodações para a recreação em ambiente fechado. Apresentaremos aqui os tipos mais comuns de tais acomodaçôes, que poderão existir isoladamente ou ser englobadas numa só edificação - o chamado "centro de recreação da comunidade." 
O centro de recreação. E' uma edificação que serve a muitos objetivos, achando-se comumente localizada dentro de um campo de recreio, como já apontamos. Inclui várias acomodações, como as que se seguem:

Ginásio - com amplo local para jogos de quadra, atividades variadas, ben como escaninhos, instalações sanitárias e lugar para os espectadores. Se tiver cadeiras soltas, de abrir e fechar, poderá haver maior aproveitamento do espaço para outras atividades recreativas (como bailes, por exemplo).

Eutuditótio - ou salão para assembléias, servindo a reuniões, produções teatrais e demais atividades que exijam placo elevado em sala espaçosa. Dispõe de local para a guarda do material, sendo comum ter cadeiras sôltas para a maior flexibilidade da sua utilização. E' importante assegurar boa acústica, iluminação adequada e distribuição eficiente das portas de entrada e saída, tendo em vista a boa circulação do público.

Sala de música - (se possível com discoteca). ${\left({ }^{\star}\right)}^{*}$

Sala para artes e trabalhos manuais.

Sala para sedes de clubes e reunióes de pequenos grupos.

Salão para jogos ativos de mesa (como o pingue-pongue, por exemplo).

Local para jogos tranqüilos de mesa (xadrez, damas etc.).

Bibjioteca $\left({ }^{*}\right)$ e sala de leitura.

Pequenos museus (de vários tipos). $\left({ }^{\star}\right)$

Piscina interna.

Acomodações para os recreadores, instalações sanitárias, almoxarifado, armários, sala de primeiros socorros, sala de repouso e pequena cozinha.

\section{ALGUMAS CONSIDERAÇÕES SÔBRE O EQUIPAMENTO DOS PARQUES INFANTIS DE RECREAÇÃO}

"Gangorras ou gramados não fazem um parque de recreação. Embora andar horas a fio numa gangorra seja coisa mais saudável, não é menos insipida do que ficar junto a um caça-níques; num salão de jôgo"... "Um trepa-trepa tem mais valor do que um carrossel; um material variado, para construção, possui mais importância do que mesas de tênis. Mas não iremos banir, é claro, as mesas de tênis e as gangorras. Só queremos recomendar o reconhecimento dos valores criadores na recreação. O objetivo nãe será divertir, mas inspirar para ações criadoras e originais". ("Pro Juventude" - Suiça).

Ao selecionar os aparelhos para os parques de recreação, é preciso levar se em conta as seguintes exigências: segurança; a contribuição que podem prestar ao desenvolvimento total da criança; sua adequação ao grupo

(*) Evidentemente, o programa municipal de recreação manterá equipes volantes dêsses serviços, para percorrer os vários centros de recreação. 
de idade que os vai utilizar; sua resistência a um uso intenso e à exposição ao tempo; seu custo; sua facilidade de instalação, substituição e reparo; e a economia da sua manutenção.

Sern pretender descer a pormenores sôbre os aparelhos recomendáveis para os parques infantis de recreação, que escapariam ao âmbito dêste trabalho, mas tendo em vista, apenas, que o principal objetivo de tais organizações é funcionar para as crianças, queremos citar algumas experiências bem sucedidas, com material simples (se não improvisado), em parques europeus e norte-americanos.

A tendência atualmente encontrada nos parque de recreação é a de complementar (quando não substituir) os aparelhos tradicionais, como gangorras, balanços, ou escorregas, por equipamento de forma, digamos assim, menos cristalizada, por aparelhos de utilização mais flexivel, por material que favoreça atividades realmente recriadoras. Esta mesma idéia vem dominando, aliás, os passatempos dos adultos (os "hobbies") com a expansão crescente do movimento do "do-it-yourself", em que o principal não é o restultado obtido, mas a participação ativa das pessoas. Em lugar de se dar valor apenas ao produto final, procura-se mobilizar as capacidades humanas e concentrá-las no próprio processo de fazer as coisas, o que constitui, sem dúvida, objetivo essencial no desenvolvimento de uma personalidade criadora.

Apontamos, como exemplo típico disto, o "Robinson Playground" (nome tirado do engenhoso Robinson Crusoe) de Wipkingen, em Zurich, por sua vez inspirado nos "Skrammelplädser" da Dinamarca e da Suécia. Nêle encontramos : um recanto para os pequeninos, com balanços, argolas, barras, caixas de areia, trepa-trepa, gangorras, um encantador tanque d'água (construído com seções transversais de grossos canos, colocados em alturas diferentes, de modo a constituírem bacias ligadas por água corrente, a fazer uma cascatinha), a aldeia das crianças (contendo três pequenas casas mobi liadas e uma loja com balcões cheios de latas vazias de mantimentos), um trem feito de manilhas justapostas, de pouco mais de $1,00 \mathrm{~m}$, tôdas perfuradas lateralmente a intervalos regulares, para fingir janelas e assegurar boa supervisão, uma área calçada para brincadeiras de bola de gude, "amarelinha", "cinco marias", patinação etc., na qual existe, ainda, um pavilhão para os dias de chuva e as brincadeiras de casa; um teatrinho simples ao ar livre, para as dramatizações e as festas das crianças, perto do qual vê-se um bonde velho, doado ao parque (onde as crianças divertem-se a grande), um prédio para a recreação social (com sala de leitura, biblioteca infantil, uma sala para artes manuais); um campo para jogos, constituído por uma área grande, arborizada; e, por fim, uma área para as atividades de construção - cnde as próptias crianças erguem suas cabanas, tôrres, lojas, utilizando o terrenc como bem o queiram. Neste último setor, encontram-se tábuas, canos, bancos de carpinteiro, arame, ferramentas, enfim, o material mais diversificado possivel para as aventuras infantis. Além disto, há no parque inúmeras paredes especialmente preparadas, onde os freqüentadores podem fazer desenhos a lápis, esponja e giz. Nêle existem, outrossim, bancos para os acompanhantes das crianças. 
Os setenta aprque de Stockholm são atendidos por recreadores formados em curso de longa duração, cujos salários situam-se no mesmo nível que o dos professôres de classe. Em todos os parques, há uma separação nítida entre as áreés para as crianças maiores e as menores, sendo que, em vários dêles, encnntram-se aldeias de brinquedo, com as suas casinhas mobiladas, as quais devem ser reservadas (por um dia) pelas crianças interessadas, com a devida antecedência. Três dêsses parques pertencem ao grupo dos chamados "adventure playgrounds", em que é possivel fazer tôda sorte de construções e esculturas, com o material que lá se encontra. Nos jardins, comumente existentes nesses parques, as crianças encontram ainda. oportunidade de cultivar a terra, podendo levar para casa as flôres que ali nascem, graças aos seus cuidados.

A Dinamarca, que como a Suécia, já conta com uma experiência de meic século em parques, orgulha-se de ter originado tais "parques de aventuras" - os "Skrammelplädser", criados há mais de quinze anos sob a inspiração de Sorenson. Em Kopenhagen, existem mais de cento e trinta "playgrounds", onde, além dos aparelhos tradicionais (balanços, trepa-trepa, gangoras), há caixas de areia, tanques para brincadeiras com água, tábuas, caixotes e material ratıado para construção, bem como áreas destinadas ao embelezamento da paisagem.

Em Emdrup, por exemplo, funciona um parque de aventuras em que não hà gastos com o material utilizado pelas crianças pois êle é todo doado (tábuas, batricas, pregos, ferramentas, sementes etc.). Muito comumente vêem-se nesses parques barcos imprestáveis - os quais, não obstante, representarn elemento de grande atração para as crianças - e esculturas feitas pelos próprios freqüentadores. No mais antigo dêles, existe, a par de uma oficina construida pelas crianças e onde elas executam trabalhos manuais, um automóvel velho, em que todos os mistérios de um motor de explosão podem ser sondados por mãozinha ávidas.

De grande beleza e motivo de atração para as crianças são, ainda, aquêles troncos desgalhados de uma enorme árvore morta, que se deitou num dêsses parques, a formar um trepa-trepa original.

Na Inglaterra, funcionam alguns "adventure playgrounds", em Londres e em Silssex, onde as crianças constroem suas cabanas e "cavernas", cavam e fazem demolições, brincam numa caixa de areia que elas mesmas planejaram e executaram, escondem-se numa casizhola que pintaram, cozinham ao ar livre, "viajam" em escaleres velhos e, diàriamente, lavam e arrumam as suas cabanas, tudo sob a orientação de recreadores especializados.

Em Hansa-Viertel, Berlim, encontra-se equipamento atraente e leve. inteiramente construído com tubos metálicos de pequeno calibre, como um "túnel" e uma "gaiola" de desenho original.

Nos E.U.A.A., cuja "National Recreation Association" conta com mais de cinqüenta anos de serviço eficiente, funcionam 18.000 "playgrounds", dentre os quais queremos destacar alguns em Philadelphia, Oakland, Berkeley e Baton Rouge, nos quais podemos ver o novo "Sculptural playground equipinent", inspirado de início nas esculturas do sueco Egon 
Möller. Existern no país aproximadamente 7.000 profissionais, que dão tempo integral à recreação (não só nos parques, mas também nos hospitais, fábricas etc.), sendo que só no ano letivo de 1956-57, formaram-se 554 recreadores em sessenta e duas escolas de nivel superior, como prova irrefutável do prestígio de que goza a profissão.

Para finalizar, citemos alguns exemplos de equipamento fartamente encontrado em tais parques: um trem feito de manilhas e madeira; um trepa-trepa todr: de cordas; balanços improvisados com pneumáticos velhos; aviōes, automóveis, vagões de trem e caminhões imprestáveis; um "labirinto" aberto ("dodger" ou "maze"), que propicia inúmeras brincadeiras de correr, trepar e equilibrar.se. Nos chamados "junkplaygrounds", que correspondem aos parques de aventuras, encontra-se material de tôda sorte, para construção. caixotes, grandes cubos, tábuas, blocos ocos de madeira, painéis de avião cheios de mostradores, botões, biombos feitos de pranchas para separar as diferentes áreas etc., etc.

Passemos egora, ao

\section{PLANO PRELIMINAR DAS FACILIDADES DE RECREAÇÃO PÚBLICAS PARA BRASILIA}

A guisa de primeira sugestão, a ser revista após o completamento dos estudcs indicados no item 7 e o exame dos urbanistas, propomos as seguintes facilidades materiais para a recreação em Brasilia, tendo em vista o plano geral da cidade, de acôrdo com o especificado no item $8 b$ (I e II), e levando em conta o plano do sistema escolar apresentado pelo I.N.E.P.:

1. Dois lotes de recreio para cada quadra, que abrigará de 2.500 a 3.500 habitantes. Uma destas áreas há de localizar-se junto ao jardim de infância, embora não deva ficar sob a sua responsabilidade. (Os pais ou outros voluntários cuidarão das crianças que aí brincarem, valendo-se apenas das instalações sanitárias do jardim de infância, convenientemente dispostas para atender a êste duplo serviço.)

2. Um parque de recreação para cada quatro quadras, onde se situará a escola-parque.

3. Um campo de recreação junto a cada escola média, como parte integrante do Centro de Educação Média, que atenderá a cada conjunto populacional de 45.000 habitantes.

4. Ulm campo de recreação, com maior desenvolvimento das facilidades para as práticas desportivas, junto à futura universidade.

5. $U_{m}$ estádio municipal, em ponto central da cidade, provido de amplo local para o estacionamento de carros.

6. Um teatro ao ar livre com concha acústica.

7. Parques de vizinhança (nos quais incluir-se-ão praças e jardins). e um grande parque (com locais para piqueniques, "atividades aquáticas e 
jogos), tudo a ser distribuido de acôrdo com a topografia do local, as belezas raturajs, a aproveitar, bem como a densidade e o tipo de população das várias zonas da cidade.

8. Locais para acampamentos (pelo menos dois, sendo um diurno e outro de pernoite), piscinas públicas, colônias de férias e zonas de conservação da natureza (em especial de reservas florestais).

9. Facilidades especiais para a recreação nos conjuntos residenciais, internatos, hospitais e fábricas.

\section{B I B L I O G R A F I A}

1. Durle, Bradley. "Community Plannitg for Human Services". - New York: Columbia Univ. Press, 1952.

2. ButLER, George D. "Recreation Areas - their Design and Equipment. Playgrounds". New York: Barnes, 1947.

3. Eurrek, George D. "Introduction to Community Recreation". (Ed. rev.) New York: McGraw - Hill, 1949.

4. "Community Recreation Comes of Age". Washington, D. C.: Federal Security Agercy. 1944.

5. Erikson, Erik Homburger. "Childhood and Society". New York: W. W. Norton, 1950.

6. Gnimion, Siegfried. "Mechanization Takes Command". London: Oxford Univ. Press, 1948.

7. Gioss, G. M. "Recreational Research". Bâton Rouge, La: Ortlieb Printing Co., 1940.

8. "Guide for Planning Recreation Parks in California". California Committee on Recreation, Park Areas and Facilities, Sacramento, Calif., 1956.

9. HAviGiurst, Robert J. "Leisure Activities and the Socioeconomic Status of Children". In American Journal of Sociology, LIV (1949) $505-19$.

10. Havighurst, Robert J. "Developmental Tasks in Education". New York: Longman, Green, 1.952.

11. Hurzinga, Johan. "Homo Ludens, el Juego y la Cultura". (Trad.) Mexico: Fondo de Cultura Econômica, 1943.

12. "Kinderspielplätze". Munchen : Georg. D. W. Callway, 1958.

13. LOEB, Harold. "Life in a Technocracy": New York: Viking Press, 1933.

14. Mead, Margaret e Rhoda MÉtraux. "The Study of Cultures at a Distance". Chicago. Univ. Of. Chicago Press, 1953.

15. Nationa' Council on School House Construction..."Guide for Planning School Flants". Nashville: The Council, 1951. 